\title{
Research on Application of Metacognitive Strategies to Business English Reading Teaching
}

\author{
Zi-Rui WANG \\ School of Foreign Languages, Nanyang Institute of Technology, Nanyang, Henan \\ ziruiwang05@126.com
}

Keywords: Metacognitive strategies, Business English teaching, Business English reading competence.

\begin{abstract}
This paper investigated whether metacognitive strategy training could improve the students' awareness of metacognitive strategy use and their business English reading competence. In order to find the result, the author launched an experimental research by employing O’Mally \& Chamot's metacognitive strategy teaching method-CALLA (Cognitive Academic Language Approach) into business English reading teaching. The questionnaire about the students' awareness of metacognitive strategy use and business English reading test were conducted before and after the experiment; an interview was also made after the experiment. Then, data were collected and analyzed. The results of the study shows that metacognitive strategy training has a positive effect on developing students' own individualized strategy systems and improve their business English reading efficiency.
\end{abstract}

\section{Introduction}

Metacognitive theory is firstly put forward by American psychologist Flavell in the 1970s. According to him, metacognition can be simply defined as cogniton about cognition, which means the individual could plan, monitor, control, evaluate, and regulate his cognitive strategies to gain the purposes in a cognitive way. Metacognitive strategies are various measures and skills using by the learners in their learning management. Metacognitive strategy refers to learners' thinking in their cognitive process, and it is the regulatory measures in order to succeed in their study, such as planning, monitoring and evaluating. Metacognitive strategy is a high level of management skills and the requirement for successfully planning, monitoring and evaluating of learning activities. It plays a core role for improving the learning effect. Since its birth, metacognition has been an important branch of educational psychology. It has already been applied to English language teaching, especially in English reading teaching. A lot of researches have revealed that the use of metacognitive strategy can improve the students' reading ability.

Although many researches home and abroad have demonstrated that metacognitive strategy training has positive impact on the students' reading ability and improving learning effectiveness, there are rare studies on applying metacognitive strategies to business English reading teaching. On the other side, the domestic learning and teaching of business English reading is far from satisfactory, especially in some local colleges. On the one hand, students' business English reading proficiency is low since they have low interest in the course learning and seldom plan, monitor and evaluate their study by themselves. On the other hand, business English teaching in many local colleges mainly adopts the traditional grammar-translation method which is obsolete, less effective and hard to raise students' interest. Therefore, how to improve the efficiency of business English reading teaching become the main concern for both teachers and students. In view of these problems in business English reading, the author of this paper applies the metacognitive strategies to business English reading teaching, with the purpose of improving the students' business English reading proficiency.

In order to validate whether metacognitive strategy training could improve the students' business English reading ability, the author has launched an experimental research by employing O’Mally \& Chamot's metacognitive strategy teaching method-CALLA into business English reading teaching. 
CALLA is short for Cognitive Academic Language Learning Approach. Up to now, this model is regarded as the most reasonable and effective learning strategy training model by the foreign language teaching area and is widely used in foreign language teaching. CALLA emphasizes that learning strategies are "taught explicitly". Its most impressive feature is that it changes the traditional teacher-centered class activities into the student-centered activities, while the teachers only direct if necessary. In each CALLA lesson, there are usually five instructional stages: preparation stage, presentation stage, practice stage, evaluation stage, and expansion stage. These five stages are not necessarily followed the order strictly and they can follow a spiral order.

This research is mainly to probe into the effect of metacognitive strategies on business English reading, with a view to working out the following questions: 1) What are the effects of metacognitive strategy instruction on students' business English reading competence? 2) Does metacognitive strategy training improve the students' awareness of metacognitive strategy use? 3) Do the students' beliefs and attitudes towards business English learning undergo any changes as a result of the training?

\section{Research Design}

In order to find out the effect of metacognitive strategies on business English reading, 60 junior students were selected as the research subjects. They were business English majors from two intact classes with 30 students each. One class was chosen as the experimental class (EC) and the other as the control class (CC). The experimental class was instructed with the metacognitive strategies while the control class was taught in the traditional way. The teacher, also the author of this study, followed O'Malley \& Chamot's CALLA as the model to teaching metacognitive strategies. To make CALLA better integrate with business English reading class, the author made some modification and divide the metacognive strategy training into five stages. The following is a brief description of each stage in CALLA.

1) Preparation stage: During this stage, it is necessary to find out what students have already known, i.e. the students' previous knowledge about the contents and strategies. The main purpose of preparation stage is to help students come to know their prior knowledge of the strategies that they might already have been using.

2) Presentation stage: The presentation phase focuses on new information presenting. The teachers can through a variety of ways to show specific learning strategies training activities. The strategies likely to be taught in this stage are self-monitoring, elaboration and influence.

3) Practice stage: In practice stage, students practice and use new information appearing in the presentation phase in many ways. Students are the center in this phase. Students absorb the new information and apply new strategies in different classroom activities. Meantime, many strategies are practiced in this phase such as self-monitoring, planning, summarizing, deduction, elaboration.

4) Evaluation stage: Evaluation phase allows the students to check their performance so that they can have a clear idea about what they have already learned and what they need to improve. Through this stage, the students' metacognitive awareness can be developed. Learning strategies in this stage include self-evaluation, elaboration, cooperation and self-talk.

5) Expansion stage: In this stage, teachers need to explain to students the importance of switching learning strategies to the new task, and how to apply them in the new tasks. In addition students could be given chances to apply strategies to other learning or reading tasks appropriately.

In this teaching experiment, four instruments, namely, tests, questionnaire, interviews, and SPSS software were employed to collect and analyze the data and information. A pretest and a posttest were employed in this study to evaluate students' business reading comprehension. Cambridge Business English reading tests (Vantage) were used as the test paper. As is well known that BEC test enjoys high reliability and validity in the world. The main skill employed in BEC reading test is to skim and scan for general and specific business in authentic business environment. No doubt, BEC test can provide valid and reliable evaluation of students' business reading strategies and competence. Questionnaires were designed to collect data about the effect of metacognitive strategy instruction on the subject's use of metacognitive strategies in their business English reading. The 
questionnaires were designed with the reference to Oxford's (1990) questionnaire. Some changes were made according to the real situation of the business English reading course. The instrument involved in the qualitative part was two interviews with 10 students chosen randomly from the participants of the experimental class. The interview was carried out at the end of the experiment to gather further information about the effect of metacognitive strategy training on business English reading.

Covering a span of 16 weeks from March to June in 2010, the whole experiment follows the following procedures: 1) Two intact classes were chosen as subjects. One class was regarded as the experimental class, and the other as the control class. 2) At the very beginning of the experiment a questionnaire was carried out to collect information about the students' metacognitive strategies use. And the content was noted and combed by the researcher later. 3) After the questionnaire, a pretest of business English reading was conducted among these two groups to collect information of their current business English reading competence. 4) A new English learning strategy-metacognitive strategies was introduced to the experimental class. And then all the members of this class were received the metacognitive strategy instruction in their business reading course, following the researcher's guidance and requirements. Students in the controlling class did not receive this training and they just followed the traditional business reading courses. 5) At the end of the semester, the posttest of business English reading was carried out among both the experimental class and the control class. The purpose of this test was to check whether there were any differences in spoken English competence between the two classes after 16-week experience of different teaching methods. 6) Another questionnaire copies were distributed among the experimental class and the control class to get in-depth information about the students metacognitive strategies use. 7) After that, an interview was held to find out whether the students' attitude changes towards business English reading after the metacognitive strategy training. 8) Data and information gotten from the tests, questionnaire and interviews were collected and analyzed with the help of SPSS 13.0

\section{Data Analysis}

After the experiment, the data were analyzed by SPSS13.0. The data collected from the pretest was first analyzed, and a comparison was made between the experimental class and the control class.

Table 1 Comparison of Pretest Scores Between EC and CC

\begin{tabular}{|cl|r|r|r|c|}
\multicolumn{8}{|c|}{ Group Statistics } \\
\hline & Class & $\mathrm{N}$ & Mean & Std. Deviation & $\begin{array}{c}\text { Std. Error } \\
\text { Mean }\end{array}$ \\
\hline pretest & EC & 30 & 30.6667 & 6.10445 & 1.11452 \\
& CC & 30 & 30.7333 & 4.67520 & .85357 \\
\hline
\end{tabular}

Independent Samples Test

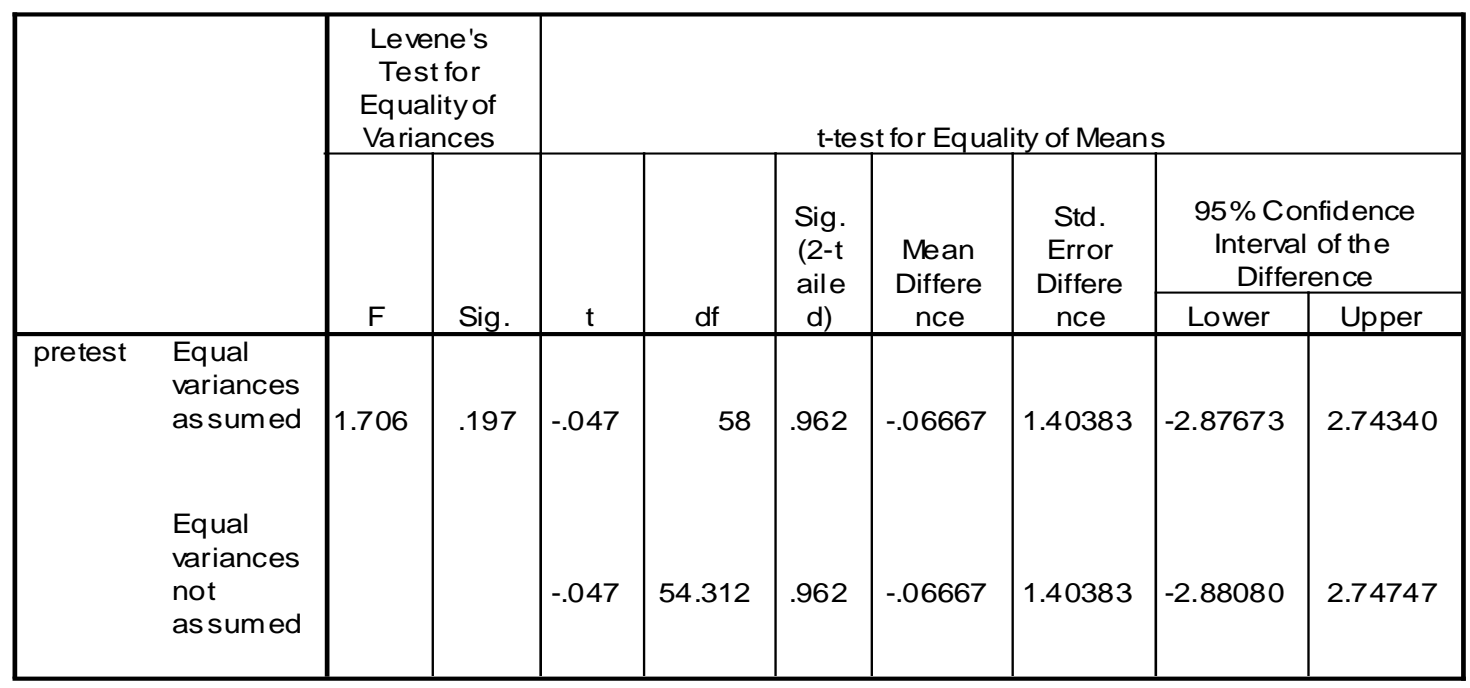


As is shown in Table 1, the means of EC and CC are respectively 30.6667 and 30.7333. There is only 0.0666 point difference between the two means. The Sig. (significance) value in Levene's Test for Equality of Variances is 0.197 which is much higher than significance level 0.05 . So it can also conclude that the variance of the two groups is equal. The Sig. (2-tailed) value is 0.962 which exceeds 0.05. The Sig. (2-tailed) value implies that the difference between EC and CC in the pretest is not significant. For $95 \%$ Confidence Interval of the Difference, there is a " 0 " value between the Lower value (-2.87673) and the Upper value (2.74370), which indicates that the difference between the means of EC and CC is not significant. Based on the analysis of Table 1, the author reaches a conclusion that the participants of the experimental class and the control class are at roughly the same proficiency level in terms of English speaking competence before the experiment.

Table 2 Comparison of Posttest Scores Between EC and CC

\begin{tabular}{|ll|r|r|r|r|}
\multicolumn{8}{l|}{ Goup Statistics } \\
\hline & Class & $\mathrm{N}$ & Mean & Std. Deviation & $\begin{array}{c}\text { Std. Error } \\
\text { Mean }\end{array}$ \\
\hline posttest & EC & 30 & 35.3667 & 5.97399 & 1.09070 \\
& CC & 30 & 31.7333 & 6.56497 & 1.19859 \\
\hline
\end{tabular}

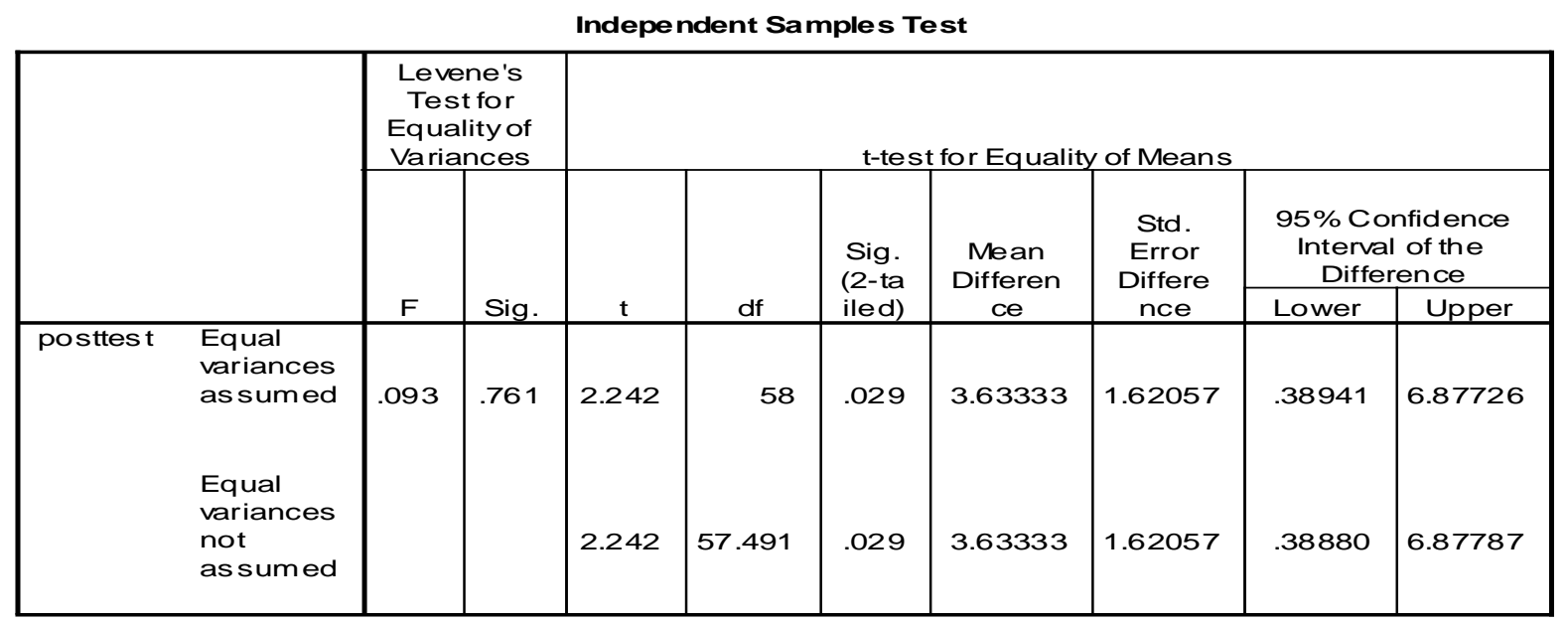

Table 2 shows that, in the posttest, the experimental class and the control class were quite different in the means (EC is 35.3667, while CC is 31.7333). The mean of EC is higher by 3.6334 points than that of CC in the posttest. The Sig. (2-tailed) value is 0.029 which is less than 0.05 , which implies that the difference in the variable of posttest between EC and CC is significant. For 95\% Confidence Interval of the Difference, there does not include " 0 " value between the Lower value (0.38941) and the Upper value (6.87726), which indicates that the difference between the means of EC and CC is significant.

According to the analyses of Table 2, the subjects of the experimental class have made great progresses in their productive competence of reading after about one semester's experiment. On the contrary, in the control class, the subjects' English reading performance is improved a little.

Table 3 Comparison of the Scores of EC Between the Pre-questionnaire and Post-questionnaire

\begin{tabular}{|c|c|c|c|c|c|}
\hline & & Mean & $\mathrm{N}$ & Std. Deviation & $\begin{array}{l}\text { Std. Error } \\
\text { Mean }\end{array}$ \\
\hline $\begin{array}{l}\text { Pair } \\
1\end{array}$ & prequestionnaire & 91.8000 & 30 & 11.30578 & 2.06414 \\
\hline
\end{tabular}

Paired Samples Cor relations

\begin{tabular}{|ll|r|r|r|}
\hline & $\mathrm{N}$ & Correlation & Sig. \\
\hline $\begin{array}{l}\text { Pair } \\
1\end{array}$ & $\begin{array}{l}\text { prequestionnaire \& } \\
\text { postquestionnaire }\end{array}$ & 30 & .981 & .000 \\
\hline
\end{tabular}




\section{Paired Samples Test}

\begin{tabular}{|c|c|c|c|c|c|c|c|c|c|}
\hline & & \multicolumn{5}{|c|}{ Paired Differences } & \multirow[b]{3}{*}{$\mathrm{t}$} & \multirow[b]{3}{*}{ df } & \multirow{3}{*}{$\begin{array}{l}\text { Sig. } \\
(2-t \\
\text { aile } \\
\text { d) }\end{array}$} \\
\hline & & \multirow[b]{2}{*}{ Mean } & \multirow{2}{*}{$\begin{array}{c}\text { Std. } \\
\text { Deviation }\end{array}$} & \multirow{2}{*}{$\begin{array}{l}\text { Std. } \\
\text { Error } \\
\text { Mean }\end{array}$} & \multicolumn{2}{|c|}{\begin{tabular}{|c|} 
95\% Confidence \\
Interval of the \\
Difference
\end{tabular}} & & & \\
\hline & & & & & Lower & Upper & & & \\
\hline $\begin{array}{l}\text { Pair } \\
1\end{array}$ & $\begin{array}{l}\text { prequestionnaire - } \\
\text { postquestionnaire }\end{array}$ & -11.46667 & 2.20866 & .40324 & -12.29139 & -10.64194 & -28.436 & 29 & .000 \\
\hline
\end{tabular}

The data in Table 3 indicates that the means of pre-questionnaire and post-questionnaire of EC are 91.8000(medium level) and 103.2667(high level) respectively. The mean has a gap of 12.4666. However, this may be not a sufficient proof that there is significant difference between the two variables. Paired Samples Correlations Test is used to verify the correlation between the two variables. The correlation coefficient is 0.981 which exceeds 0.05 and the significance level is 0.000 . Therefore, there is a strong positive correlation between the two variables. In paired sample test, for 95\% Confidence Interval of the Difference, it does not include " 0 " value which indicates that the difference between the two variables is significant. The Sig. (2-tailed) value is 0.000 , far less than 0.05 , which implies that the difference between the pretest scores and the posttest scores of EC is highly significant.

The analysis of Table 3 shows us that the experiment is successfully improving the application of metacognitive strategies in EC. The students' metacognitive strategy use level in EC is improved from medium level to high level. However dates from the control classes indicated that the control classes had gained little progress in their metacognitive strategies use under the traditional teaching method.

An interview was employed after the pretest to investigate the subjects' opinions about the present business English reading class and their attitudes towards the effect of metacognive strategies on their business English learning. 10 students chosen randomly from the experimental class were interviewed to give their opinions about metacognive strategy training. Each of the ten interviewees received an individual interview with the researcher. The researcher paid careful attention to the interviewees' description, which was given below.

With one exception nine of the ten interviewees stated that metacognive strategy training was of great help. They felt happy about this method. Eight students found read original business articles not as difficult as they imagined before. They felt business reading no longer boring, but interesting. In addition, seven of the ten interviewees had formed a habit of reading Business Week, Economist after class. Six students realized that they tended to learn much more quickly and better after they tried to put the newly learnt strategies into use. Nine interviewees remarked that their reading ability was improved, their reading speed became faster, and they became more confident to pass BEC (Vantage). Seven students said that they loved business English reading class, which was a surprise for them. However, there were some negative responses. For example, one interviewee said that evaluation in class was a waste of time. Another one reported that his English reading competence was still poor. After much observation, the author found that more students got involved in class activities and there was a good relationship between the teacher and the students as well as a more harmonious atmosphere in class.

So it is safe to conclude that metacognive strategy training not only serves to arouse students' interest in business English learning, but also is of vital significance to develop their initiative reading habits.

The analyses of the data from the tests and questionnaires, along with the information from the interview all serve well to show that Metacognitive strategy training has a positive effect on students' business English reading competence and it can improve the students' awareness of metacognitive strategy use. 


\section{Conclusion}

According to the results of this study, the following findings can be easily drawn. Firstly, through the instruction process, students in the experimental group are exposed to various metacognitive strategies, which were beneficial to them. From questionnaires before experiment, it was shown that those students have a medium level of metacognitive strategies use, but they could promote and develop metacognitive strategies after training. The results of statistic analysis revealed that their strategy awareness had been strengthened after training. Explicit metacognitive strategy-based instruction can help the students develop their own individualized strategy systems, and explore ways of learning the target language more effectively.

Secondly, the metacognitive strategy training in business English reading is more effective than the traditional one. Based on the result of analysis from the questionnaire and test papers, it could be indicated that the experimental group outperformed the control group in their reading proficiency. Thus, the metacognitive strategy training seems to have contributed to the students' ability to improve their business English reading efficiency.

Thirdly, according to the record of the interview, metacognitive strategy training leads to greater self-confidence and promoted interest and autonomy. Just as Cohen (1994) pointed out: "Strategy training can enhance students to find their own pathways to success, and thus it promotes learner autonomous and self-direction.” After metacognitive and strategy-based instruction, some students in the experimental group have learned to choose their own strategies and to do so spontaneously. Their confidence and interest in business English learning have improved a lot.

In a word, metacognitive strategy training has a positive effect on student's business English learning. Under this instruction, students can make their own choices, and apply strategies to their language studies so as to become more effective learners. Based on the findings of this research, the author gives the following suggests for the business English reading teaching:

1) Business English reading teachers should strengthen their metacognitive strategy awareness and integrate metacognitive strategy training in the classroom teaching. The applications of metacognitive strategies not only improve students' business English reading ability, but also cultivate independent readers which are quite useful for the student's future study and work. The teacher must be serious about the metacognitive strategy training, providing students with abundant practice opportunities and reading task.

2) Before metacognitive strategy training, it is necessary for the teachers to implement metacognitive knowledge and metacognitive strategies to student. This activity can activate students' previous unconscious metacognitive strategic awareness, which is quite helpful for the following metacognitive training.

3) In metacognitive strategy training, the teachers should try their best to create a free active learning atmosphere in which students are active to involve in thinking, discussion and evaluation. The center of the classroom activate should transferred from teachers to students. The teachers model, guide, stimulate rather than dominate. The students no long the passive receivers but the active participants by using various reading strategies to seek answer for reading tasks.

4) The teachers should provide various opportunities to students to utilize metacognitive strategies. Only through enough practices, the use of metacognitive strategies can be internalized into the student's minds. Then the students can use those strategies automatically which can help to cultivate skilled readers.

\section{References}

[1]Alderson, J. C. Assessing reading [M]. Cambridge: Cambridge University Press, 2000.

[2]Anderson, N. J. The role of metacognition in second language teaching and learning [J]. Education Resources Information Center, 2002

[3] Chamot, A. U., \& O'Malley, J. M. The CALLA handbook: Implementing the cognitive academic language learning approach [M]. White Plains, NY: Addison Wesley Longman, 1994. 